\title{
Analysis of obstetric and gynecological surgeries among adolescent girls: lessons for prevention
}

\author{
Ruchi Kalra*, Jyoti Nath Modi
}

Department of Obstetrics \& Gynaecology, People's College of Medical Sciences and Research Centre, Bhopal, Madhya Pradesh, India

Received: 17 January 2015

Accepted: 18 February 2015

\author{
*Correspondence: \\ Dr. Ruchi Kalra, \\ E-mail: drruchi.kalra15@gmail.com
}

Copyright: ( ) the author(s), publisher and licensee Medip Academy. This is an open-access article distributed under the terms of the Creative Commons Attribution Non-Commercial License, which permits unrestricted non-commercial use, distribution, and reproduction in any medium, provided the original work is properly cited.

\begin{abstract}
Background: Health of adolescent girls is a priority. Any operative surgery affects her physical \& psychological health adversely. Aim: The study was done to analyze the operative burden on adolescent girls and identify the health needs of adolescent girls at our institute.

Methods: A cross sectional study was done from May 2010 till Aug 2013. All adolescent girls (19 years age and below) operated during this period at department of obstetrics \& gynaecology, People's college of medical science \& $\mathrm{RC}$, Bhopal were included.

Results: The operations were done on 54 adolescent girls during this period which was $1.37 \%$ of the total surgeries. Age wise distribution was as $50 \%$ were of 19 years age, $37 \%$ were 18 years, $7.4 \%$ were of 17 years and $5.5 \%$ were 16 years and below. $41 \%$ of them were admitted with labour complaints, $26 \%$ cases as abortions, $13 \%$ cases with pain in abdomen. $11 \%$ of cases had cyclical pain with primary amenorrhoea $5 \%$ were admitted with Primary amenorrhoea, $4 \%$ had complaints of perineum pain. Maximum surgeries for obstetrical indications were caesarean sections (41\% cases) followed by suction evacuation for abortion(26\%). Among gynecological surgeries, maximum were done for imperforate hymen \& partial vaginal septum (11\% casesexploratory laparotomy for benign ovarian masses $(9.25 \%$ cases). Diagnostic laparoscopy for primary amenorrhea was done (5.5\% cases) and operative laparoscopy (3.7\% cases). $1.85 \%$ cases each were of pelvic abscess and bartholin cyst where I\&D and marsupialization were done respectively.

Conclusions: Obstetric operative burden on adolescent girls was very high. $67 \%$ of obstetric related surgeries can be prevented by educating and encouraging them to delay the onset of sexual activity and also by providing health related and contraceptive advices in schools and community settings.
\end{abstract}

Keywords: Adolescent girls, Gynaecological operations, Adolescent friendly services

\section{INTRODUCTION}

The term adolescence is derived from the Latin word "adolescere" meaning to grow, to mature. Adolescence is a transitional phase from childhood to adulthood. It is a period of significant and dramatic change spanning over the physical, biological, social, and psychological aspects. Adolescence phase is between 10-19 years. As per 2009 estimate there are 1.2 billion adolescents (10-19 years) in the world of which 243 million adolescents are in India, being the home for $20 \%$ of world's adolescents population further of which 105 million are females. ${ }^{1}$ There has been emerging concerns on the health of adolescent girls which has now become a priority globally as health issues during this time may not only affects adolescent immediately but may also have functional long term implications in their lives. There is a felt need to provide friendly health care services to them. Life is not just living but living in good Health. The physical and psychological changes makes adolescent girl 
more vulnerable. Any health problem specially related to reproductive health is crucial at this developing age. Any gynaecological condition leading to operative procedure affects her physical \& psychological health adversely. The parents and family also gets concerned about the future fertility of adolescent girl. These adolescent girls are also hesitant to seek medical advice

Aim: The study was done to analyse the operative burden on adolescent girls and identify the health needs of adolescent girls.

\section{Objectives}

1) To estimate the operative surgeries performed on the adolescents girls at tertiary health care centre in last 3 years.

2) To analyse the clinical presentations and indications of all the operations done on adolescent girls during the study period.

3) To understand the need of adolescents and make our services adolescent friendly.

\section{METHODS}

A descriptive cross sectional study was done from May 2010 till August 2013. All adolescent girls (between 10 years to 19 years) those who were admitted with any obstetrical or gynaecological complaint and underwent operations during this period at department of obstetrics \& gynaecology, People's college of medical science \& research centre, Bhopal were included in the present study. A retrospective, record based study was carried out to estimate the operative burden on adolescent girls. The various clinical presentations for which they were admitted, their age distribution, diagnosis and operative indications were analysed.

\section{RESULTS}

54 adolescent girls between age 10 to 19 years were operated during the study period from May 2010 till Aug 2013. The records were analysed. The total number of surgeries performed during this period were 3933. The surgeries done on adolescent girls were $1.37 \%$ of the total surgeries done during this period.

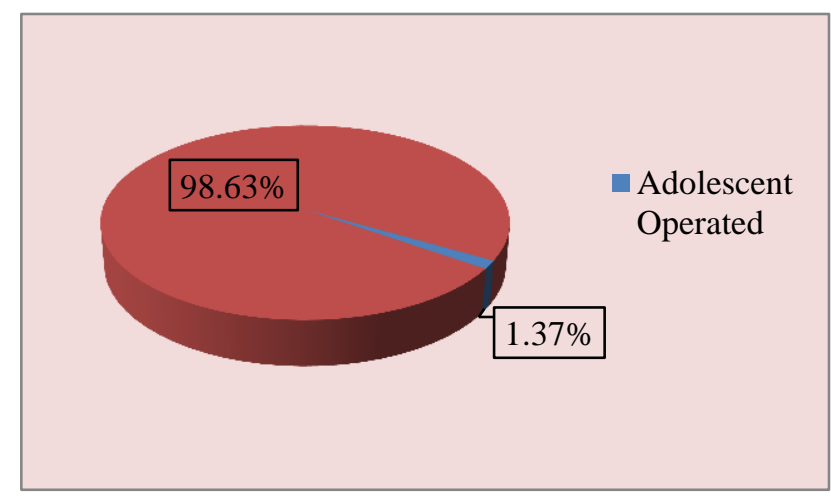

\section{Figure 1: Percentage of total adolescent surgeries.}

Age wise distribution was as following. $50 \%$ cases were of 19 years age, $37 \%$ were of 18 years, $7.4 \%$ cases were of 17 years, $3.7 \%$ cases were of 16 years and $1.85 \%$ cases were of 13 years.

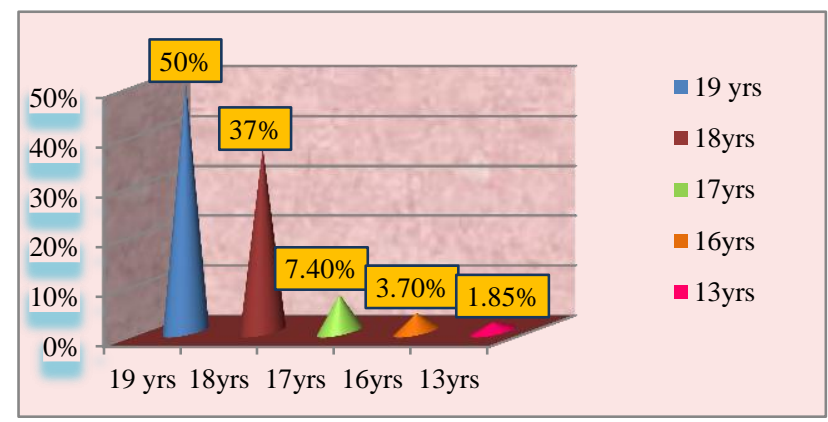

Figure 2: Age wise distribution of cases.

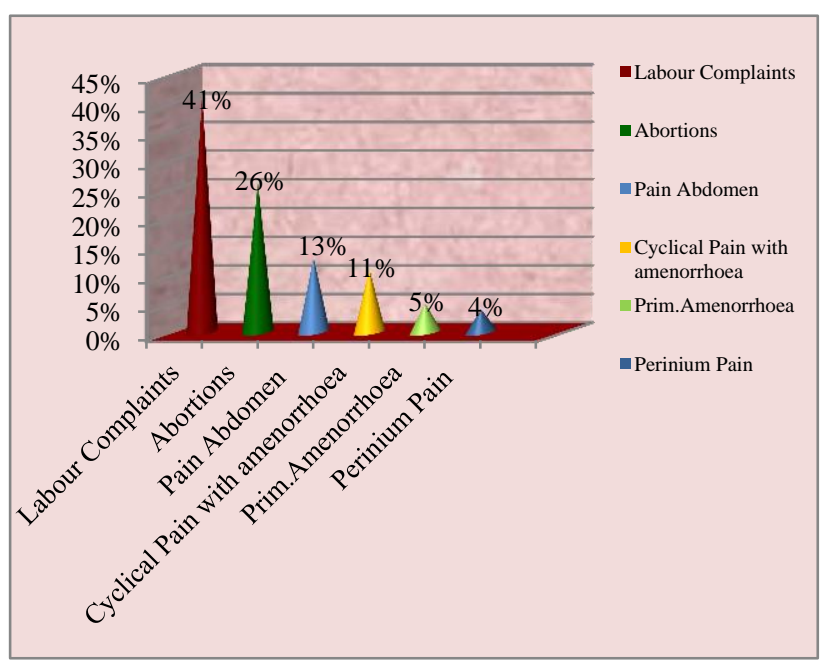

Figure 3: Clinical presentation.

$41 \%$ of adolescent girls were admitted with labour related complaints and underwent caesarean section. $26 \%$ cases had reported with amenorrhoea of short duration followed by bleeding $\mathrm{p} / \mathrm{v}$ diagnosed as either inevitable, incomplete, missed abortions, 1 case was diagnosed as vesicular mole. In $13 \%$ cases admission was done for Pain in abdomen needing further Investigation. $11 \%$ of cases had cyclical pain with primary amenorrhoea $5 \%$ of adolescent girls were admitted with only Primary amenorrhoea without pain. $4 \%$ cases had complaints of perineum pain.

Amongst these adolescents various Indications were analysed for which surgeries were performed. The operative procedures were largely sub categorized as obstetrical or gynaecological causes related operations. Among all the surgeries performed obstetrical indications had the maximum share of $67 \%$ (36 cases) and rest $33 \%$ (18 cases) cases were done for gynaecological 
indications. $\mathrm{Z}$ test of Proportion was applied and $\mathrm{P}$ value was found to be statistically highly significant $(<0.0001)$.

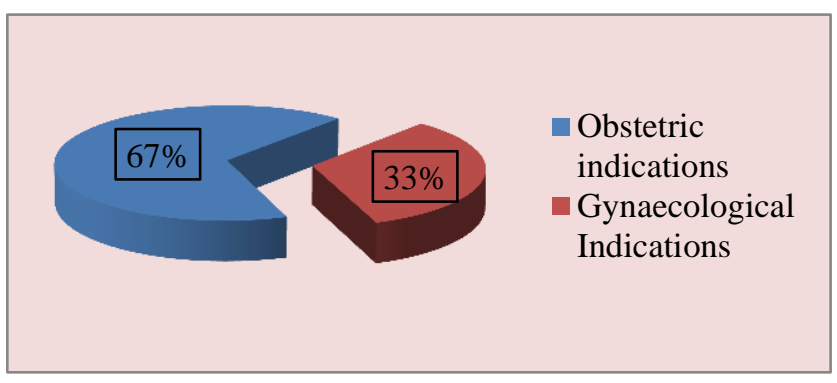

Figure 4: Indications of operations.

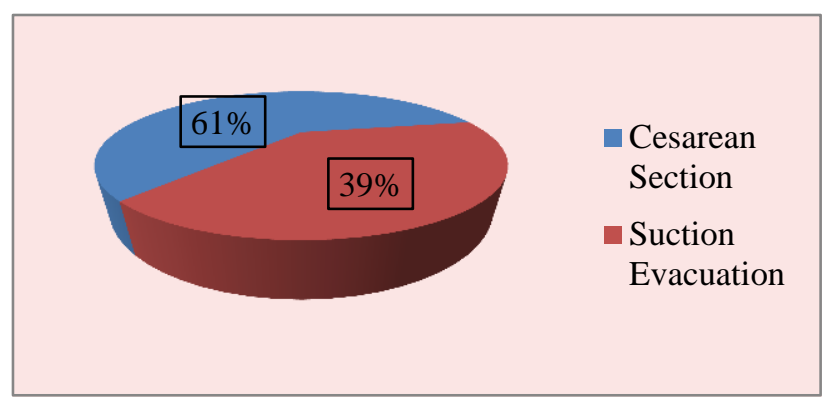

Subgroup analysis of 36 obstetrics cases was done. Maximum number of surgeries were caesarean section in $61 \%$ (22) cases and suction \& evacuation was done in $39 \%$ (14) cases for abortions diagnosed either incomplete, inevitable or missed, one case was of vesicular mole. $\mathrm{Z}$ test of proportion was applied and $\mathrm{P}$ value was found to be statistically significant $(<0.05)$.

Among gynaecological surgeries maximum number were done for imperforate hymen by giving cruciate incisions and vaginoplasty for partial transverse vaginal septum $(11 \%$ cases) presenting as haematocolpos or haematometra. Exploratory laparotomy was done for benign ovarian masses in $9.25 \%$ cases. Diagnostic laparoscopy for primary amenorrhoea was performed in $5.5 \%$ cases. All of these were diagnosed as Meyer Rokintansky Kusher Hauser syndrome. Operative laparoscopy for simple ovarian cyst was done in $3.7 \%$ cases. One case $(1.85 \%)$ was of pelvic abscess for which incision and drainage was done and one case $(1.85 \%$ cases) was Bartholin cyst for which incision, drainage and marsuplization was done. $\mathrm{Z}$ test of proportion was applied and $\mathrm{P}$ value was found to be statistically significant $(<0.05 \%)$. Table 1 , indications of operations performed.

Figure 5: Sub group analysis of obstetrical indications.

Table 1: Showing diagnosis and operations performed.

\begin{tabular}{|c|c|c|c|c|c|}
\hline & Diagnosis & Operations performed & $\begin{array}{l}\text { No. of } \\
\text { cases }\end{array}$ & $\begin{array}{l}\mathrm{Z} \\
\text { value }\end{array}$ & $\begin{array}{l}P \\
\text { value }\end{array}$ \\
\hline \multirow{2}{*}{$\begin{array}{l}\text { Obstetrical } \\
\text { causes }\end{array}$} & Labour related problems & Caesarean section & $41 \%(22)$ & \multirow{8}{*}{2.2411} & \multirow{8}{*}{0.025} \\
\hline & Abortions & Suction evacuation & $26 \%(14)$ & & \\
\hline \multirow{6}{*}{$\begin{array}{l}\text { Gynaecological } \\
\text { causes }\end{array}$} & $\begin{array}{l}\text { Imperforate hymen, transverse } \\
\text { vaginal septum }\end{array}$ & Cruciate incision vaginoplasty & $11 \%(6)$ & & \\
\hline & Benign ovarian tumour & Exploratory laparotomy & $9.25 \%(5)$ & & \\
\hline & $\begin{array}{l}\text { Primary amenorrhoea } \\
\text { (MRKH syndrome) }\end{array}$ & Diagnostic laparoscopy & $5.5 \%(3)$ & & \\
\hline & Simple ovarian cyst & Laparoscopic cyst dissection & $3.7 \%(2)$ & & \\
\hline & Bartholin abscess & Marsupialization drainage & $1.85 \%(1)$ & & \\
\hline & Pelvic abscess & Incision \& drainage & $1.85 \%(1)$ & & \\
\hline
\end{tabular}




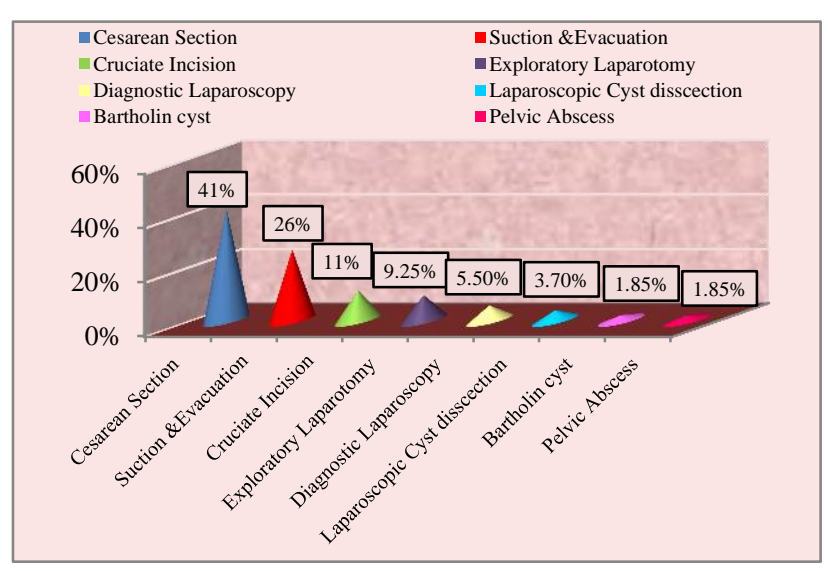

Figure 6: Indications of operations performed.

\section{DISCUSSION}

The present study was done with the aim to estimate the operative burden on adolescent girls. This was done to access the health care operative needs of these young girls who shy off from coming to hospital so as we can provide them more approachable adolescent friendly services.

225 million adolescent population comprises of $22 \%$ of India's total population. Female comprises of $47 \%$ of adolescent population and $20 \%$ of female adolescents are already married before 15 years of age and are already mothers. More than $70 \%$ of girls of age group 10-19 years suffer from moderate or severe anaemia .Mortality rate is higher in 15-19 years group. Also unmet need of contraception is high in this group. The results of our study has shown that $67 \%$ of cases had undergone surgery for obstetrical indications. These data reflects the ARSH, RCH II stated figures. ${ }^{2}$ WHO facts sheet on adolescent pregnancy (updated September 2014) states that there has been a marked, although uneven, decrease in the birth rates among adolescent girls since 1990, but some $11 \%$ of all births worldwide are still to girls aged 15 to 19 years old. The vast majority of these births $(95 \%)$ occur in low- and middle-income countries. ${ }^{3}$

The teenage pregnancy is considered as high risk pregnancy. They are three times more at risk of developing anaemia, pre-term labour and two times more chance of developing Pregnancy induced hypertension and its related complications. ${ }^{4}$ The girl declaration is a call to action to put girls at the heart of the post-2015 development agenda. It aims to halve the number of girls becoming pregnant before the age 18 by 2030 and Provide universal access to youth-friendly health info and services, regardless of marital status or pregnancy. ${ }^{5}$ The abortions were the second highest obstetric indication for which these girls underwent suction evacuation. Educating and encouraging the adolescents to delay the onset of sexual activity and also providing them health related and contraceptive advices in schools and community settings, youth centres, mobile health centres and by e-health education.

Strategy for ARSH (Adolescent reproductive sexual health) has been approved as part of the National RCH II Programme Implementation Plan (PIP). This strategy focuses on reorganizing the existing public health system in order to meet the service needs of adolescents. Steps are to be taken to ensure improved service delivery for adolescents during routine check-ups at sub centre clinics and to ensure service availability on fixed days and timings at the PHC and CHC levels. This is to be in tune with the outreach activities. A core package of services would include preventive, promotive, curative and counselling services. It describes the intended beneficiaries of the adolescent friendly reproductive and sexual health services (target group), the health problems/issues to be addressed (service package) and the health facilities and service providers to be involved. Such friendly services are to be made available for all adolescents, married and unmarried, girls and boys during the clinic sessions, but not denied services during routine hours. Focus is to be given to vulnerable and marginalized sub-groups. A plan of service provision as per level of care may be developed based on the RCH II service delivery plan. ${ }^{6}$

$11 \%$ of surgeries in present study were done for imperforate hymen and transverse vaginal septum and another 5\% were diagnosed as Mayer-RokitanskyKüster-Hauser (MRKH) syndrome by diagnostic laparoscopy. It is suggested that laparoscopy helps in precise diagnosis of the MRKH condition ${ }^{8}$ Mullerian anomalies incidence is for 1 in $4500 .^{7}$ Occurrence of Imperforate hymen is 1 in 2000 and giving a cruciate incision is a simple way of its treatment. ${ }^{9} 9.25 \%$ of cases underwent exploratory laparotomy for Benign ovarian tumors and $3.7 \%$ cases were operated by laparoscopic approach. Compared with laparotomy, laparoscopy is associated with less bleeding, adhesions and postoperative pain, faster recovery and a better cosmetic result. These benefits are even more valuable in an adolescent population. Faster recovery allows patients to return to their schooling, while less adhesions formation may reduce future fertility issues. ${ }^{10}$ In another study by Claire Templeman and co-workers also suggested laparoscopy as justified approach for the young girls. ${ }^{11}$ In a study by Bhattacharyya and co-workers also reported high incidence of ovarian tumours during adolescent age group. $^{12}$

\section{CONCLUSION}

Present study showed obstetric operative burden on adolescent girls was very high, $41 \%$ caesarean sections and $26 \%$ evacuations for abortions. These $67 \%$ of obstetric related surgeries can be prevented by educating and encouraging them to delay the onset of sexual activity and also by providing adolescents friendly health 
related and contraceptive advices in schools and community settings.

Funding: No funding sources

Conflict of interest: None declared

Ethical approval: The study was approved by the institutional regulatory body

\section{REFERENCES}

1. UNICEF. National family health survey, 2005-06. In: IIPS, eds. IIPS Survey. Mumbai, India: IIPS; 2007.

2. NRHM. Adolescent reproductive sexual health (ARSH) RCH II, 2014. Available at: www.nrhm.gov.in/arsh

3. World Health Organization. Facts sheet: Adolescent pregnancy, 2014. Available at: http://www.who.int/mediacentre/factsheets/fs364/en/ . Accessed September 2014.

4. Mahavarkar SH, Madhu CK, Mule VD. A comparative study of teenage pregnancy. J Obstet Gynaecol. 2008;28(6):604-7.

5. The Girl Effect. The girl declaration, 2014. Available at: www.girleffect.org/the-girl-effect-in-action/girldeclaration.

6. Government of India. Implementation guide on $\mathrm{RCH}$ II adolescent reproductive sexual health strategy. In: GOI, eds. GOI Guide. India: Ministry of Health and Family Welfare; May 2006.
7. Karine Morcel, Laure Camborieux, Daniel Guerrier. Mayer-Rokitansky-Küster-Hauser (MRKH) syndrome. Orphanet J Rare Dis. 2007;2:13.

8. Alfonsa Pizzo, Antonio Simone Laganà, Domenico Puzzolo. Mayer-Rokitansky-Kuster-Hauser syndrome: embryology, genetics and clinical and surgical treatment. ISRN Obstet Gynecol. 2013;2013:628717.

9. Chelli D, Kehila M, Sfar E, Zouaoui B, Chelli H, Chanoufi B. Imperforate hymen: can it be treated without damaging the hymenal structure? Sante. 2008 Apr-Jun;18(2):83-7.

10. Pandis GK, Michala L, Creighton SM, Cutner AS. Minimal access surgery in adolescent gynaecology. BJOG. 2009;116:214-9.

11. Claire Templeman, Mary E. Fallat, Alexandra Blinchevsky, S. Paige Hertweck. Non-inflammatory ovarian masses in girls and young women. Am Coll Obstet Gynecol. 2000 Aug;96(2):229-33.

12. Nirmal Kumar Bhattacharyya, Anuradha De, Rajat Bandopadhyay. Ovarian tumors in pediatric age group - a clinicopathologic study of 10 years' cases in West Bengal. Indian J Med Paediatr Oncol. 2010 Apr-June;31(2):54-7.

DOI: $10.5455 / 2320-1770 . i j \operatorname{cog} 20150413$

Cite this article as: Kalra R, Modi JN. Analysis of operative burden on adolescent girls: a cross sectional study. Int J Reprod Contracept Obstet Gynecol 2015;4:355-9. 